\title{
Fontes e recursos de informação tradicionais e digitais: propostas internacionais de classificação
}

\author{
Fernanda Maria Melo Alves \\ Universidad Carlos III de Madrid - UC3M, Espanha \\ Bruno Almeida dos Santos \\ Universidade Federal da Bahia - UFBA, Brasil
}

REVIEW

\begin{abstract}
Resumo
Objetivo. O estudo tem como objetivo estudar diferentes propostas internacionais de classificação de fontes e recursos de informação.

Método. Apresenta uma revisão bibliográfica sobre vários conceitos e definições, tais como dado, informação e conhecimento em contexto tradicional e digital, analisa definições, conceitos e classificações de fontes e recursos de informação, apresentadas num quadro cronológico, que facilita a identificação de suas concordâncias e discordâncias.

Resultados. Os resultados sugerem que, embora os estudos sobre fontes e recursos de informação sejam preocupação de vários autores e organizações, é necessário continuar a aprofundar e refletir sobre eles e acompanhar sua rápida evolução.

Conclusões. O novo paradigma educativo universitário requer dos docentes, investigadores e profissionais da informação esforços para preparar os estudantes a procurar, encontrar, avaliar e usar a informação e transformá-la em conhecimento para a tomada de decisões em sua vida individual e profissional, incrementar o gosto pela aprendizagem ao longo da vida e agir como cidadãos ativos e solidários, atuando na construção da sociedade democrática.
\end{abstract}

Palavras-chave

Classificação; Fontes de informação; Formação; Recursos de informação

\section{Traditional and digital information sources and resources: some international classifications}

\begin{abstract}
Objective. The study aims to analyse some different international classifications on information sources and resources. Method. The research presents a bibliographic review on concepts and definitions, as data, informationn and knowlidge, in traditional and digital context, analyses some classifications of information sources and resources, presented in a chronological table, that facilitates the identification of their agreements and disagreements.

Results: The results allow affirming that studies of information sources and resources are a concern of different authors and organizations, but they need depth and reflection, in order to follow their constant and increasingly development.

Conclusions. The new university educational paradigm requires the efforts of teachers, researchers and information professionals to prepare students to search for, find, evaluate and use information, to transform it into knowledge for decision-making in their individual and professional lives, to increase their appreciation of lifelong learning, to be active and supportive citizens, and to act in the construction of a democratic society.
\end{abstract}

Keywords

Classification; Information sources and resources 


\section{Introdução}

A atual sociedade caracteriza-se pela grande quantidade de informação proveniente de várias fontes e armazenada em unidades próprias para sua guarda, tratamento e disseminação, as unidades de informação, como os arquivos, bibliotecas, centros de documentação, centros de informação, museus, memoriais, centros de referência e outros. A informação é um recurso importante para as organizações e tem se tornado um fator de impacto social, produtivo, econômico, político, cultural, psicológico e pessoal no mundo contemporâneo.

Neste sentido, é necessário entender as fontes e recursos de informação e seu papel na sociedade, disponíveis nas unidades de informação, indispensáveis para que os profissionais da informação possam responder às necessidades de informação dos usuários, das instituições, empresas e países. Wilson (1981), baseando-se em estudos psicológicos, refere-se a três tipos de necessidades humanas: fisiológicas (comida, abrigo, água, etc.); afetivas, que também se denominam psicológicas ou emocionais (desafios, domínio, etc.); e cognitivas (planificar, aprender, etc.). Nesta perspectiva, o autor propõe substituir o termo necessidades de informação por busca de informação dirigida à satisfação de necessidades.

Diante do exposto, este artigo parte dos seguintes problemas: quais as fontes e recursos de informação, tradicionais e digitais, onde os usuários podem buscar informação para resolver seus problemas? quais as classificações propostas por diferentes investigadores sobre fontes e recursos de informação?

\section{Informação, sociedade e aprendizagem}

De acordo com Capurro e Hjorland (2007), a palavra informação tem raiz latina - informatio - e é usada em dois contextos básicos: o ato de moldar a mente e o ato de comunicar o conhecimento. Porém, sua origem é grega, como informam estudos de Seiffert (1968) e Schnelle (1976), nos quais Capurro (1978) encontrou explicações sobre o étimo latino e seu desenvolvimento subsequente.

Nos dicionários consultados por Ferreira (2004), a palavra informação é definida como o ato de informar alguma coisa ou o resultado desse ato. Moraes (2002) afirma que:
A informação, [...] sempre é a representação de algo [...], a partir de uma seleção no universo de saberes. [...], segundo determinados interesses ("olhares") que se sobressaem de acordo com as relações de poder e produção de saberes/tecnologias. [...] a partir de específicos recortes da realidade, fragmentando-a segundo as intenções sobre o que destacar camuflar, deturpar... (Re) ligando os fragmentos sob uma determinada e específica ordenação.

Acrescenta o mesmo autor que a variedade de conceitos referentes à palavra informação vai crescendo, segundo os interesses da sociedade da informação: sejam interesses acadêmicos, que disputam a prioridade da propriedade ou mesmo novas organizações epistemológicas em busca de afirmação de status de ciência primordial da informação; sejam interesses econômicos, que enfatizam o aspecto pragmático e operacional das atividades de informação; ou mesmo políticos e sociais, que destacam a função de dominação ou libertação que a informação vem ocupando na sociedade contemporânea.

Por outro lado, a palavra informação é empregada em várias áreas científicas com conceitos diferentes, impossibilitando uma definição unanimemente aceita (SOPER; OSBORNE; ZWEIZIG, 1990; CAPURRO; HJORLAND, 2007) e dificultando a transmissão do conhecimento entre elas (PORTELA, 2005).

\subsection{Dado, informação e conhecimento}

O processo de criação do conhecimento baseia-se nos conceitos dado, informação e conhecimento, e nas relações que se estabelecem entre eles, concebidos como parte de uma ordem sequencial, fundamentais para a comunicação humana (DAVENPORT, 1998; DEVLIN, 1999).

O dado é uma unidade básica de informação, não processada, associada a um objeto ou fato e representada por números ou símbolos estruturados; a informação é um conjunto de dados que compõem uma mensagem, na forma de documento ou algum tipo de comunicação, passível de interpretação e de sentido, que surge como conhecimento ao ser interpretado e utilizado, e combinado com a experiência e capacidade humana (CORNELLÁ, 2000). 
Relacionando informação e conhecimento, Shera (1990) esclarece que informar é um processo ou atividade, enquanto conhecer é um estado mental. O conhecimento é o estado de saber organizado, é tudo o que se aprendeu ou assimilou valores, fatos ou informações, enquanto a informação é uma atividade para obter conhecimento. Cornellá (2000) sintetiza esta explicação, afirmando que a informação não é necessariamente conhecimento.

A informação desempenha um papel fundamental do ponto de vista econômico, social, cultural e individual, baseada nas novas tecnologias da informação e comunicação (TIC), que permitem mudanças significativas em sua produção e distribuição, para as quais são indispensáveis competências, que abarcam um conjunto de habilidades e atitudes, que permitem ao ser humano desenvolver-se, de forma integrada e eficaz, ao longo da vida.

No contexto educativo e profissional, o uso da informação articula-se com a autonomia na aprendizagem e na investigação, de modo a formar profissionais competentes e capazes de se adaptar às contínuas mudanças e ao desenvolvimento profissional; no âmbito individual, vincula-se ao exercício da cidadania ativa e à participação democrática. Entretanto, as discussões sobre essas tecnologias, como parte do processo de aprofundamento das mudanças da sociedade e seus impactos educacionais, ainda não têm recebido a devida atenção (UNESCO, 2010).

As habilidades em informação são fatores-chave na aprendizagem ao longo da vida e o primeiro passo na consecução das metas educacionais de qualquer aprendiz. Os profissionais de informação, os elementos da comunidade do ensino-aprendizagem e os especialistas na gestão da informação devem assumir o papel principal no ensino da competência em informação, por meio da criação de programas integrados aos currículos, em colaboração com os professores, e contribuir ativamente com o processo educativo dos alunos (LAU, 2008).

\subsection{A informação nas sociedades da informação, do conhecimento e da aprendizagem}

Articulados os conceitos de dado, informação e conhecimento, convém integrá-los ao contexto atual. A evolução tecnológica permitiu que alguns teóricos conceituassem a nossa sociedade como da informação. Jamil e Neves (2000) referem-se às modificações efetuadas com o surgimento de novas ferramentas, equipamentos, capacitações e especializações, disponíveis ao homem atual para a melhoria do seu padrão de vida.

Rezende e Abreu (2000) estabelecem uma relação entre os conceitos em estudo e explicam que informação é todo o dado trabalhado, útil, tratado, com valor significativo atribuído ou agregado a ele, e com um sentido natural e lógico para quem usa a informação. O dado não transmite nenhum conhecimento, ou seja, não contém um significado claro. Quando a informação é "trabalhada" por pessoas e pelos recursos computacionais, possibilitando a geração de cenários, simulações e oportunidades, transforma-se em conhecimento.

Para que as informações constituam a base do conhecimento, sua aquisição implica o desencadear de operações intelectuais, relacionando os novos dados com as informações armazenadas, adquirindo-se conhecimento quando elas se inter-relacionam, criando uma rede de significações que se interiorizam, bem ao contrário das perturbações provocadas pelas mídias, que fazem com que o homem creia ter acesso ao significado dos acontecimentos, simplesmente porque recebeu informação sobre eles (PELLICER, 1997).

Vivemos em tempos de grandes mudanças no meio econômico, político e social. É neste contexto que Castells (1999) anuncia e fundamenta o aparecimento da sociedade da informação, em que

Uma nova economia surgiu em escala global nas últimas duas décadas. Chamo-a de informacional e global [...], porque, sob novas condições históricas, a produtividade é gerada, e a concorrência é feita em uma rede global de integração. E ela surgiu no último quartel do século XX porque a Revolução da Tecnologia da Informação fornece a base material indispensável para esta nova economia. 
Destaca o mesmo autor as principais características desse novo paradigma: a informação é a sua matériaprima, a capacidade de penetração dos efeitos das novas tecnologias, a lógica de redes, a flexibilidade e a convergência de tecnologias específicas para um sistema altamente integrado (CASTELLS, 2002), características diretamente relacionadas com o processo de democratização do saber, fazendo emergir novos espaços para a busca e o compartilhamento de informações, em que não há barreiras de acesso a bens de consumo, produtos e comunicação.

Krüger (2006) verifica que, em muitas publicações, o termo sociedade da informação foi sendo substituído por sociedade do conhecimento e sociedades de saberes, termos adotados pela UNESCO, pela OCDE e pelos governos para promover estratégias políticas, o que implica uma mudança conceitual da informação ao conhecimento, considerando-o como princípio estruturador da sociedade moderna e ressaltando sua importância para a sociedade atual e as mudanças dos mercados laborais, da educação e da formação.

Para que a sociedade da informação possa ser considerada uma sociedade do conhecimento é imprescindível que se estabeleçam critérios para organizar e selecionar as informações, pelo que a dinâmica da sociedade da informação requer educação continuada ao longo da vida, que permita ao indivíduo não apenas acompanhar as mudanças tecnológicas, mas, sobretudo, inovar (TAKAHASHI, 2000).

As reflexões apresentadas convergem com os "quatro pilares" da educação defendidos por Delors (1999), a noção de sociedade aprendente, em que o sucesso dos indivíduos depende da sua capacidade de processar e gerir a informação e, sobretudo, da sua adaptação à mudança (OCDE, 2000), e a defesa da liberdade intelectual e o acesso à informação, essenciais à cidadania efetiva e responsável e à participação na democracia (IFLA/UNESCO, 1999). Neste contexto, a informação e o conhecimento, fundamentos da Ciência da Informação, estão disponíveis nas fontes e recursos de informação.

\section{Fontes e recursos de informação}

O acesso ao conhecimento cristaliza os problemas inerentes à privacidade, exatidão e propriedade e os principais meios ao seu acesso são a informação e a instrução em informática (MCGARRY, 1999). Embora Sabor (1967) não defina o termo, expõe o que podem ser as fontes de informação, enquanto Katz (2002) afirma que uma fonte de informação é qualquer obra que se usa para responder a uma pergunta, uma explicação demasiado abrangente.

\subsection{Conceito e definição}

Consultadas várias obras de referência, optou-se pela definição do Online Dictionary of Library and Information Science About the Dictionary (ODLIS, 2002), adequada à abordagem deste estudo, em que se define fonte de informação como qualquer documento que forneça informações solicitadas por um escritor, investigador, usuário de biblioteca ou pessoa que esteja pesquisando num catálogo online ou num banco de dados bibliográficos. Também se refere a um documento que fornece informações copiadas ou reproduzidas em outro documento, por exemplo, uma citação ou um trecho.

É unanime a constatação de que o estudo e a publicação de literatura sobre fontes de informação na América do Sul e Central têm como percursora Josefa Sabor, que publicou em 1957 o primeiro livro sobre este tema, Manual de fuentes de información, atualizado, aumentado e traduzido (Figura 1), ao longo da sua larga carreira de docente, investigadora, autora e assessora de políticas de educação e de informação, cujo legado ainda perdura (ROMANOS DE TIRATEL, 2012). 

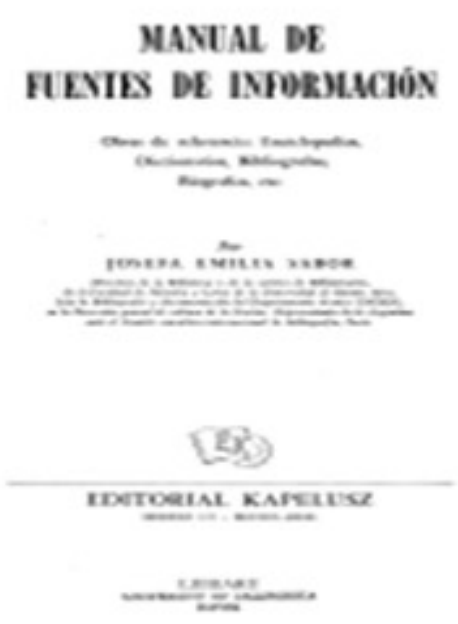

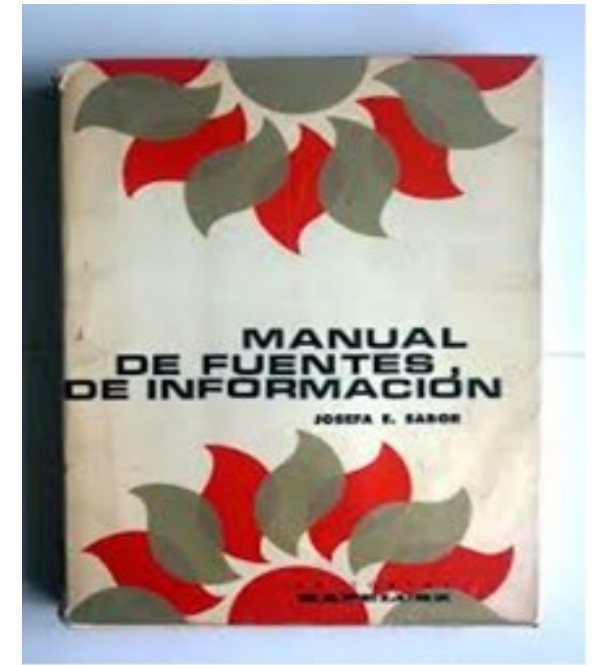

Fonte: Google Imagem.

Ao longo da sua história, o Brasil tem acompanhado as mudanças tecnológicas e científicas, com repercussão nas transformações sociais. Sob uma perspectiva institucional, as professoras Campello e Campos, reconheciam "[...] a precariedade das coleções, suas falhas e deficiências, bem como a falta de instrumentos bibliográficos que permitam ao bibliotecário tomar conhecimento do que existe, isto é, identificar material para formar seu acervo." (CAMPELLO; CAMPOS, 1993).

No entanto, destacam-se as preocupações de docentes, pesquisadores e instituições de ciência e tecnologia, patentes em algumas publicações pioneiras que, não sendo as únicas, se consideram adequadas aos propósitos deste estudo:

- A análise comparativa de programas da disciplina Bibliografia, lecionada em 15 Escolas de Biblioteconomia do Brasil, que conclui que a falta de livros de texto em português parece ser a causa da disparidade do ensino dessa disciplina (GOMES, 1976).

- A elaboração de uma metodologia para a criação, desenvolvimento e automação de guias de fontes de informação, em decorrência da maior disponibilidade de uso de recursos computacionais para o estabelecimento de padrões que facilitem a geração de guias (LOBO; BARCELLOS, 1992). Esta metodologia foi aperfeiçoada, publicada pelo IBICT (1996), inserida na política de informação de ciência e tecnologia para promover o intercâmbio de dados entre os diversos centros, compartilhando guias e catálogos, e para criar bases de dados.

Alguns autores brasileiros aproximam-se das definições de fontes de informação anteriormente referidas:

- Incluem manuscritos e publicações impressas, além de objetos, como amostras minerais, obras de arte ou peças museológicas (CUNHA, 2001).

- Designam todos os tipos de meios (suportes) que contêm informações suscetíveis de serem comunicadas (ARRUDA; CHAGAS, 2002).

- Consideram qualquer livro, documento, organismo, instituição ou pessoa que transmite informação (FERREIRA, 2004). 
- Compõem-se de qualquer documento, dado ou registro que forneça aos usuários de uma unidade de informação ou serviço de informação, informações que respondam a certas demandas. Estas fontes também são necessárias para o desenvolvimento de uma organização, seja ela governamental ou não (ARAÚJO, 2013).

As fontes de informação são um instrumento de transferência da informação, que tem sua base na Bibliografia e sua evolução (MOREIRO, 1989), desde o século II antes de Cristo, até que começa a desenvolver-se como método repertorial no século XVI, quando o livro é o procedimento de transmissão do saber. A especialização do conhecimento originou técnicas e métodos que permitem parcelar um contexto científico, para poder selecionar a parte que se pretende conhecer, de forma pontual e precisa. Esta necessidade facilita o nascimento das Ciências de Documentação, que incorporam técnicas de acesso aos usuários, na forma de Fontes de Informação, nas quais a Bibliografia aparece incorporada como fator fundamental (CARRIZO, 2000).

Explica a mesma autora que a informação escrita evoluiu, transformando-se numa indústria potente, fundamentalmente devido ao avanço das TIC, que influíram na elaboração, publicação, distribuição e consulta das fontes de informação, através de suportes óticos, sistemas automatizados e redes de comunicação que, não sendo os únicos, produziram uma grande transformação na produção no acesso ao conhecimento.

As fontes de informação também têm sido identificadas com as Obras de Referência, que Villaseñor (1998) define como "[...] fontes de informação de caráter documental, utilizadas habitualmente no serviço de referência de bibliotecas e em centros de documentação, para atender as demandas informativas dos usuários", resolver dúvidas pontuais ou para iniciar-se no conhecimento de uma matéria, sendo unicamente um tipo de fonte de informação, pelo que identificar ambos os termos reduz o significado das fontes. Ambos os termos puderam ser identificados, enquanto seu suporte era unicamente o bibliográfico, mas com os novos formatos, audiovisuais, eletrônicos e digitais, o conceito ampliou-se, considerando-se fontes de informação as que contêm informação, independentemente do suporte.

Igualmente se empregam, com frequência, as expressões fontes de informação e recursos de informação e recursos eletrônicos (TEXIDOR, 2003). Rodrigues e Blattman (2011) comentam que, até o fim de 1990, as fontes de informação eram sinônimas de formato impresso, mas com o avanço das TIC e da internet, passaram a ser sinônimos de recursos de informação, disponíveis em formato digital.

Martín (2013) explica que, no mundo da informação e no jargão profissional, os dois termos, fontes e recursos de informação, adquiriram uma especial relevância no contexto das TIC e, principalmente, da internet. No entanto, as fontes são os objetos que contêm informação em qualquer tipo de suporte e os recursos são esses mesmos objetos, imersos num processo de transmissão de dados que, através de ferramentas da informática, permitem acrescentar contribuições complementares, pelo que os recursos de informação acrescentam mais valor às fontes de informação, porque facilitam o seu acesso e consulta.

Ao final dos anos de 1990 e princípios deste século, o desenvolvimento tecnológico potencializou o aparecimento da web 2.0, conhecida também como web social, que em oposição à web 1.0, apresenta uma série de serviços, que fomentam a participação e colaboração ativa dos internautas na criação e descrição dos conteúdos, em distintos formatos (O’REILLY, 2005), não exigindo conhecimento prévio sobre linguagens informáticas (GARCIA, 2009).

Para Merlo (2007), o crescimento da web e sua própria evolução transformaram-na numa das fontes mais importantes. Os profissionais da informação manifestaram capacidade para localizar e gerar diretórios, índices e resumos, repositórios de documentos, bibliotecas eletrônicas, revistas eletrônicas, bancos de dados, catálogos, portais, listas de distribuição e outros sistemas de transferência de mensagens e monografias. Arroyo (2009) revê o conceito da web 2.0 e as fontes de informação, que se apresenta na figura seguinte: 
Figura 2- Fontes de informação na web 2.0.

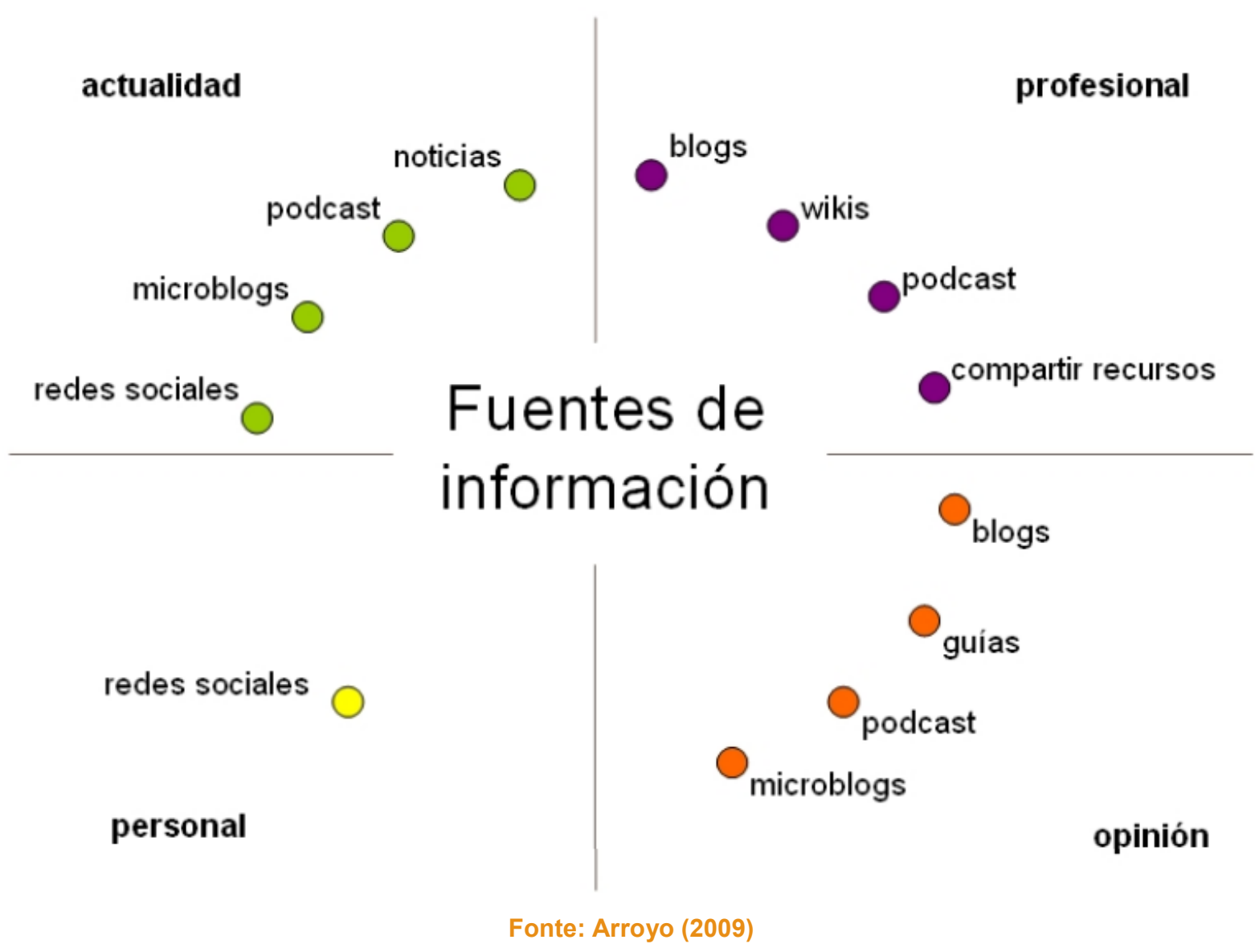

Além disso, em relação a outro tipo de fontes, a autora considera:

- Vantagens, o dinamismo, a gratuidade, o caráter informal, os conteúdos antes ocultos, os conteúdos inéditos, a facilidade de publicação, a acessibilidade, o aumento de informação e o valor acrescentado;

- Desvantagens, a dependência da participação dos internautas, a parcialidade, a fiabilidade dos conteúdos, a dispersão e fragmentação da informação, o maior grau de obsolescência e a duplicidade dos conteúdos.

Silva e Aquino (2014) destacam fontes de informação da web. 2 e alegam que, para se potencializar a aplicação das ferramentas de busca online, é necessário um contexto dinâmico, que permita orientar o usuário-aprendente à fonte desejada.

Atualizando suas publicações anteriores, Cunha (2016) enumera e descreve numerosas fontes e recursos de informação em contexto tradicional e digital, acessíveis ou não por internet, que abrangem literatura nacional e internacional.

Sobre a diferença entre fontes e recursos de informação, Moscoso (1998) adverte que o conceito de recurso de informação não é a soma de uma fonte de informação e uma ferramenta de informática, o que significaria tornar equivalente o recurso de informação com a fonte informação eletrônica. Segundo a autora, o que diferencia um 
recurso de uma fonte tradicional é sua condição iniludível de bem, seu valor econômico, conceito da sociedade atual, que atribui papel e valor fundamentais à informação.

Em consequência da evolução e aplicação do movimento de acesso aberto, desenvolvido em diferentes áreas, os cursos abertos disponibilizam-se em ambientes virtuais de aprendizagem, ferramentas da web 2.0 ou redes sociais, que incorporam recursos educacionais abertos (REA), em inglês Open Educational Resources (OER), que potencializam oportunidades e desafios no ensino-aprendizagem (HYLÉN, 2006), aos quais Zancanaro. Todesco e Ramos (2015) aplicam um estudo bibliométrico. O guia publicado pela UNESCO/COL (2011) define REA como:

[...] materiais de ensino, de aprendizagem e de investigação em qualquer suporte de domínio público, sob uma licença aberta que permite o acesso, uso, reaproveitamento, reutilização e redistribuição por outros com restrições limitadas ou não. O uso de normas técnicas abertas incentiva o acesso e o potencial de reutilização. Os REA podem incluir cursos/programadores completos, material de cursos, módulos, guias de estudantes, notas de ensino, livros didáticos, artigos de investigação, vídeos, ferramentas e instrumentos de avaliação, materiais interativos, tais como simulações e jogos, bases de dados, software, aplicações (incluindo aplicativos móveis) e qualquer outro tipo de material educativo útil.

Como progressão dos ideais de educação aberta dos REA, surgem novos recursos, os cursos online massivos e abertos, conhecidos como MOOC (Massive Open Online Course), baseados em novas teorias e abordagens do ensino-aprendizagem. A UNESCO (2011) promove seu uso, através de distintas publicações, algumas das quais orientam a elaboração de políticas e atividades no marco da Agenda de Educação 2030 e da consecução do objetivo de Desenvolvimento Sustentável 4. Paralelamente, Stachokas (2012) criou um novo sistema de classificação dos REA, denominado Scholarship, Persistence, Entity, Compatibility, and Convenience (SPECC). Mais recentemente, Ossiannilsson, Altınay e Altınay (2017) analisam a organização e a fiabilidade dos REA e expõem formas de melhorar sua usabilidade nas instituições de ensino superior e nas profissionais.

\section{Metodologia}

A pesquisa é descritiva, quanto aos objetivos, bibliográfica, quanto aos procedimentos, e qualitativa, quanto à forma de abordagem. Abrange de início, uma revisão sobre conceitos e definições de dado, informação e conhecimento, na perspectiva da Sociedade da Informação, do Conhecimento e da Aprendizagem ao longo da vida. Em seguida, desenvolve uma revisão bibliográfica sobre fontes e recursos de informação, analisando definições, conceitos e classificações. Pesquisou-se o portal da CAPES, a Biblioteca do Conhecimento Online (B-On), a Red de Bibliotecas Universitarias de España (REBIUM) e o buscador Google Scholar, que deram acesso às bases de dados, Web of Science, SCOPUS, LISA, REDALYC, SCIELO e DIALNET. Primeiro, foram delimitadas as fontes de informação na área de Comunicação e Informação e depois foram definidos os termos "fontes de informação", "fonte de informação digital" e "recursos de informação" e "recursos de informação abertos", em português, inglês e espanhol, para obter um conjunto alargado de conceitos de fontes e recursos de informação, classificações e tipologias. Selecionada a literatura adequada ao tema e à abordagem escolhida, efetuou-se uma leitura analítica do conteúdo dos documentos, para ordenar e sumariar as informações e obter respostas ao problema da pesquisa. As várias propostas de classificação das fontes e recursos apresentam-se num quadro, que facilita a identificação de suas concordâncias e discordâncias. Os resultados sugerem que, embora os estudos sobre fontes e recursos de informação sejam preocupação de vários autores e organizações, é necessário continuar a aprofundar e refletir sobre eles e acompanhar sua rápida evolução.

\section{Resultados e discussão}

Para Perec (1985), enfrentam-se sempre dificuldades metodológicas para efetuar qualquer tipo de classificação, não havendo nenhum método universal e definitivo para as classificações. Pinheiro (2006) adverte que a classificação dos documentos em diferentes categorias nem sempre é coincidente, o que se explica pela abordagem mais científica ou mais documental, dependente da visão do conteúdo, propósito ou função; mutatis mutandis, a diversidade terminológica dos conceitos de fontes e recursos de informação origina propostas classificativas heterogêneas. 
Identificam-se quase tantas classificações das fontes e recursos de informação quantos os teóricos que abordam o tema. Como propedêutica, usa-se uma classificação simples, que considera as fontes de informação divididas em três grandes categorias, primárias, secundárias e terciárias, de acordo com o conteúdo do documento e o caráter da mensagem informativa (ROMANOS DE TIRATEL, 2000).

Não é intenção de este estudo abarcar exaustivamente propostas classificativas, apenas algumas, oportunas à abordagem escolhida. Optou-se, intencionalmente, por não separar as fontes e recursos de informação em suporte impresso, digital e misto. Para facilitar uma visão de conjunto e uma análise evolutiva-comparativa, desenhou-se o Quadro 1, ordenado cronologicamente, de 1970 a 2015.

Quadro 1- Algumas propostas internacionais de classificação de fontes e recursos de informaçãoados

\begin{tabular}{|c|c|c|c|c|}
\hline Autor & Critèrios & Classificação & Data & País \\
\hline Grogan 1 & $\begin{array}{l}\text { Aplicação às } \\
\text { ciências e às } \\
\text { tecnologias }\end{array}$ & $\begin{array}{l}1 \text { Primárias (documentos originais, como revistas científicas, relatórios, anais de } \\
\text { congressos, as patentes, as dissertações, as teses, as publicações oficiais e os dados } \\
\text { de pesquisa); } 2 \text { Secundárias (remetem às originais, como: serviços de indexação e } \\
\text { resumo, revistas de periódicos sobre literatura primária), materiais de referência, } \\
\text { tratados, monografias e livros-texto); } 3 \text { Terciárias (anuários e diretórios, bibliotecas, } \\
\text { centros de informação e bibliografias). }\end{array}$ & 1970 & $\begin{array}{l}\text { Reino } \\
\text { Unido }\end{array}$ \\
\hline $\begin{array}{l}\text { Burk e } \\
\text { Horton }\end{array}$ & $\begin{array}{l}\text { Serviço ao } \\
\text { usuário }\end{array}$ & $\begin{array}{l}1 \text { As fontes de informação (indivíduo ou organização que facilita informações e } \\
\text { dados ao usuário); } 2 \text { Serviços de informação (ajuda aos usuários para encontrar } \\
\text { informações); } 3 \text { Produtos de Informação (ferramentas oferecidas ao usuário para } \\
\text { encontrar informações); } 4 \text { Sistemas de informação (processo estruturado ou } \\
\text { procedimento para coletar, organizar e distribuir informações ou dados ao usuário). }\end{array}$ & 1985 & EUA \\
\hline $\begin{array}{l}\text { Itami e } \\
\text { Roehl } 2\end{array}$ & $\begin{array}{l}\text { Para estratégia } \\
\text { empresarial }\end{array}$ & $\begin{array}{l}1 \text { Informações do contexto (capacidades de produção, informações de clientes e } \\
\text { canais portadores de informação); } 2 \text { Informação interna (cultura corporativa, moral } \\
\text { dos trabalhadores. Capacidade de gestão, capacidade da empresa de gerir } \\
\text { informação, competências capacidade dos empregados em transmitir e utilizar } \\
\text { informação para a tomada de decisões, hábitos e normas de esforço dos } \\
\text { trabalhadores); } 3 \text { Informação corporativa (reputação corporativa, imagem de marca, } \\
\text { imagem corporativa e influência sobre o canal de distribuição e seus fornecedores, } \\
\text { know-how de marketing). }\end{array}$ & $\begin{array}{l}1987 / \\
1980\end{array}$ & $\begin{array}{l}\text { Japão/ } \\
\text { EUA }\end{array}$ \\
\hline $\begin{array}{l}\text { López } \\
\text { Yepes } 3\end{array}$ & $\begin{array}{l}\text { Valor } \\
\text { económico da } \\
\text { informação }\end{array}$ & $\begin{array}{l}1 \text { Fontes de informação (empresas ou indivíduos simples que uma organização } \\
\text { adquire informação externa, o equivalente a fonte de origem); } 2 \text { Serviços de } \\
\text { informações (fornecimento de estrutura de informação dentro ou fora da } \\
\text { organização); } 3 \text { Sistemas de informação (centralização de todos os fluxos de } \\
\text { informação na organização, e é definida, como o processo estruturado onde os inputs } \\
\text { de informação são transformados em outputs }\end{array}$ & 1989 & Espanha \\
\hline $\begin{array}{l}\text { Paez } \\
\text { Urdaneta }\end{array}$ & $\begin{array}{l}\text { Organização da } \\
\text { documentação }\end{array}$ & $\begin{array}{l}\text { 1. Primárias, internas ou externas da organização. } 2 \text { secundárias, elaboradas ou não } \\
\text { dentro da organização. } 3 \text { terciárias. } 4 \text {. Bases de dados institucionais e } \\
\text { extrainstitucionais. } 5 \text {. Produtos informativos da organização, comercializáveis ou } \\
\text { resultantes da agregação de valor para a instituição ou extrainstituição disponíveis. }\end{array}$ & 1990 & Venezuela \\
\hline Lynch & $\begin{array}{l}\text { Acesso à } \\
\text { internet }\end{array}$ & $\begin{array}{l}1 \text { Catálogos automatizados de acesso público; } 2 \text { Serviços de distribuição de } \\
\text { bases de dados; } 3 \text { Catálogos coletivos em rede; } 4 \text { Listas e foros de discussão. }\end{array}$ & 1991 & EUA \\
\hline Choo & $\begin{array}{l}\text { Natureza das } \\
\text { fontes }\end{array}$ & $\begin{array}{l}1 \text { Externas e pessoais (clientes, concorrentes, contatos comerciais, profissionais e } \\
\text { funcionários de ordem governamental); } 2 \text { externas e impessoais (jornais, periódicos, } \\
\text { publicações governamentais, radio, televisão, associações comerciais, industriais, } \\
\text { conferencias e viagens); } 3 \text { internas e pessoais (superiores hierárquicos, membros da } \\
\text { diretoria, gerentes subordinados e equipe de funcionários); } 4 \text { internas e impessoais } \\
\text { (memorandos e circulares internos, relatórios e estudos internos, biblioteca da } \\
\text { organização e serviços de informação eletrônica). }\end{array}$ & 1994 & Canadá \\
\hline Kaye & $\begin{array}{l}\text { Universo } \\
\text { empresarial: } 1 \\
\text { formato; } 2 \\
\text { status; } 3 \\
\text { localização }\end{array}$ & $\begin{array}{l}1 \text { formato (oral ou documentada, textual ou audiovisual/multimídia, livros ou base de } \\
\text { dados eletrônicos); } 2 \text { status (pessoal e impessoal, formal ou informal; publicada ou } \\
\text { não publicada, confidencial); } 3 \text { localização (interna e externa). }\end{array}$ & 1995 & $\begin{array}{l}\text { Reino } \\
\text { Unido }\end{array}$ \\
\hline $\begin{array}{l}\text { Byström e } \\
\text { Järvelin }\end{array}$ & $\begin{array}{l}1 \text { Origem; } \\
2 \text { localização; } 3 \\
\text { objetivo geral } \\
\text { (relacionada } \\
\text { com a } \\
\text { informação } \\
\text { científica) }\end{array}$ & $\begin{array}{l}1 \text { Origem (internas e externas); } 2 \text { localização: a) orientada para os fatos: registos } \\
\text { (catálogos e ficheiros manuais e informatizados) e bases de dados comerciais; b) } \\
\text { orientado para o problema: pessoas envolvidas e documentos oficiais (ordens do dia, } \\
\text { atas de reuniões, cartas, candidaturas, memorandos, mapas, documentos de } \\
\text { planeamento não publicados); } \mathbf{3} \text { objetivo geral: a) especialistas (colegas } \\
\text { experientes), b) literatura (livros, relatórios, jornais, jornais), c) coleções pessoais } \\
\text { (notas pessoais, cálculos, etc.) }\end{array}$ & 1995 & Finlândia \\
\hline Atherton & Tipo e conteúdo & $\begin{array}{l}1 \text { informal (conversas, cursos, conferencias, etc.); } 2 \text { formal (publicada e não } \\
\text { publicada); } 3 \text { quantitativa (centros de dados, inventários quantitativos). }\end{array}$ & 1997 & EUA \\
\hline $\begin{array}{l}\text { Carrizo, } \\
\text { Irureta- } \\
\text { Goyena e } \\
\text { Lopes de } \\
\text { Quintana }\end{array}$ & $\begin{array}{l}\text { Nível de } \\
\text { informação }\end{array}$ & $\begin{array}{l}1 \text { primárias ou originais (livros, monografias, artigos de revistas e trabalhos } \\
\text { acadêmicos sobre investigações); } 2 \text { secundárias, que remetem às primárias } \\
\text { (bibliografias ou repertórios e catálogos); ( } 3 \text { terciárias (remetem às primárias e incluo } \\
\text { às primárias (bibliografias de bibliografias e repertórios de obras de consulta ou } \\
\text { referencia); } 4 \text { obras de referencia ou consulta, inicialmente com informação } \\
\text { suficiente e autónoma (a coleção especial de uma biblioteca). }\end{array}$ & 2000 & Espanha \\
\hline $\begin{array}{l}\text { Sugahara } \\
\text { e Jannuzzi }\end{array}$ & $\begin{array}{l}\text { Aplicada à } \\
\text { indústria } \\
\text { brasileira } \\
\end{array}$ & $\begin{array}{l}\text { Interna e externa (fontes ligadas a atividades de mercado, fontes de caráter } \\
\text { profissional, fontes especializadas e institucionais). }\end{array}$ & 2005 & Brasil \\
\hline $\begin{array}{l}\text { Pereira e } \\
\text { Barbosa }\end{array}$ & $\begin{array}{l}1 \text { Origem; } 2 \\
\text { proximidade; } 3 \\
\text { relação com a } \\
\text { mídia }\end{array}$ & $\begin{array}{l}1 \text { Origem (fontes internas e externas); } 2 \text { Proximidade (fontes pessoais e impessoais), } \\
3 \text { Relação com a mídia (fontes eletrônicas e não eletrônicas). }\end{array}$ & 2007 & Brasil \\
\hline Merlo & $\begin{array}{l}\text { Tipo de } \\
\text { informação e } \\
\text { demanda, } \\
\text { baseadas nas }\end{array}$ & $\begin{array}{l}1 \text { Informativas (manuais de obras de referencia, repertórios de obras de referencia, } \\
\text { bibliografias de bibliografias, repertórios de bases de dados, diretórios de buscadores, } \\
\text { diretórios analíticos); } 2 \text { pessoais (biografias, enciclopédias biográficas, dicionários } \\
\text { biográficos, enciclopédias, bases de dados biografias, quem é quem, diretórios de }\end{array}$ & 2009 & Espanha \\
\hline
\end{tabular}




\begin{tabular}{|c|c|c|c|c|}
\hline & tecnologias & $\begin{array}{l}\text { pessoas); } 3 \text { institucionais (diretórios de instituições, memórias institucionais, guias } \\
\text { institucionais); } \mathbf{4} \text { bibliográficas (bases de dados bibliográficos, bibliografias, } \\
\text { bibliografias analíticas, boletins de sumários, boletins de resumos, indices } \\
\text { acumulativos, repertórios de periódicos, índices de citação, catálogos de bibliotecas, } \\
\text { cataloga de editores e de distribuidores, boletins de críticas e resenhas); } \mathbf{5} \\
\text { documentais (guias de arquivos, catálogos de documentos, coleções documentais, } \\
\text { bibliotecas digitais); } \mathbf{6} \text { lexicográficas (dicionários, enciclopédias, tesauros, } \\
\text { glossários); } \mathbf{7} \text { geográficas (mapas, planos, atlas, guias geográficas, estados do } \\
\text { mundo, dicionários geográficos, enciclopédias, sistemas de informação geográfica); } 8 \\
\text { históricas (cronologias, anuários, almanaques, atlas históricos, enciclopédias, } \\
\text { monografias especializadas); } 9 \text { estatísticas (estatísticas, anuários estatísticos); } 10 \\
\text { normativas (boletins oficiais, textos legais, bases de dados jurídicas, repertórios } \\
\text { legislativos, portais de legislação); } 11 \text { temáticas (enciclopédias, manuais, tratados, } \\
\text { monografias especializadas); } 12 \text { técnicas (bases de dados de patentes, marcas e } \\
\text { normas, repertórios de patentes, marcas e normas); } 13 \text { inéditas (bases de dados de } \\
\text { literatura cinzenta, repertórios de literatura cinzenta); } \mathbf{1 4} \text { multimídias (bases de dados } \\
\text { de documentos multimídia, repertórios de documentos multimídia, buscadores } \\
\text { especializados); } \mathbf{1 5} \text { telemáticas (buscadores, índices, portais, repertórios de recursos } \\
\text { telemáticos, servidores web, sítios web, anéis temáticos, listas de distribuição). }\end{array}$ & & \\
\hline $\begin{array}{l}\text { Brum e } \\
\text { Barbosa }\end{array}$ & $\begin{array}{l}\text { Disponibilização } \\
\text { na internet }\end{array}$ & $\begin{array}{l}\text { Listas de discussão, correio eletrônico, informativos via correio eletrônico (newsletter), } \\
\text { informativos comerciais via correio eletrônico (e-mail marketing), salas de conversa } \\
\text { virtual (chat), mensageiro instantâneo (instant messenger), sítios de busca ou } \\
\text { ferramentas de busca, intranets, extranets, e os próprios sites disponíveis na web. }\end{array}$ & 2009 & Brasil \\
\hline Martín 4 & $\begin{array}{l}\text { Nível de } \\
\text { informação }\end{array}$ & $\begin{array}{l}1 \text { obras de consulta ou referência de caráter primário (anuários, atlas, dicionários, } \\
\text { diretórios, enciclopédias, estatísticas, guias, manuais e tratados); } \mathbf{2} \text { obras de } \\
\text { consulta ou referencia de caráter secundário (biografias ou repertórios, catálogos); } \\
\mathbf{3} \text { fontes de informação para o controlo da literatura cinzenta (atas de congressos, } \\
\text { relatórios técnicos e de investigação, normas, patentes e marcas, software, teses } \\
\text { doutorais e trabalhos universitários de distribuição interna, traduções). }\end{array}$ & 2013 & Espanha \\
\hline $\begin{array}{l}\text { Lubisco e } \\
\text { Vieira } 5\end{array}$ & $\begin{array}{l}\text { Autor e função } \\
\text { em relação ao } \\
\text { usuário }\end{array}$ & $\begin{array}{l}1 \text { Primárias (fonte original); artigos, livros, dissertações, teses, normas, relatórios, } \\
\text { patentes, enciclopédias e dicionários); } 2 \text { Secundárias (remetem às primárias): } \\
\text { abstracts ou resumos, índices, diretórios, bibliografias, catálogos, bancos e bases de } \\
\text { dados, guias.; } 3 \text { Terciárias (remetem às secundárias). }\end{array}$ & 2013 & Brasil \\
\hline $\begin{array}{l}\text { Silva e } \\
\text { Aquino }\end{array}$ & $\begin{array}{l}\text { Web. } 2 \text { ou } \\
\text { Web social }\end{array}$ & $\begin{array}{l}\text { Sites e websites, portais, blogs, microblogs, Youtube, redes sociais, grupos de } \\
\text { discussão ou comunidades virtuais, buscadores e metabuscadores. }\end{array}$ & 2014 & Brasil \\
\hline Villaseñor5 & $\begin{array}{l}1 \text { apresentação; } \\
2 \text { tipo de } \\
\text { informação; } 3 \\
\text { conteúdo; } 4 \\
\text { grau de } \\
\text { informação; } 5 \\
\text { suporte; } 6 \\
\text { difusão; } 7 \\
\text { assunto; } 8 \\
\text { cobertura } \\
\text { geográfica; } 9 \\
\text { cobertura } \\
\text { temporal; } \\
10 \text { ordenação }\end{array}$ & 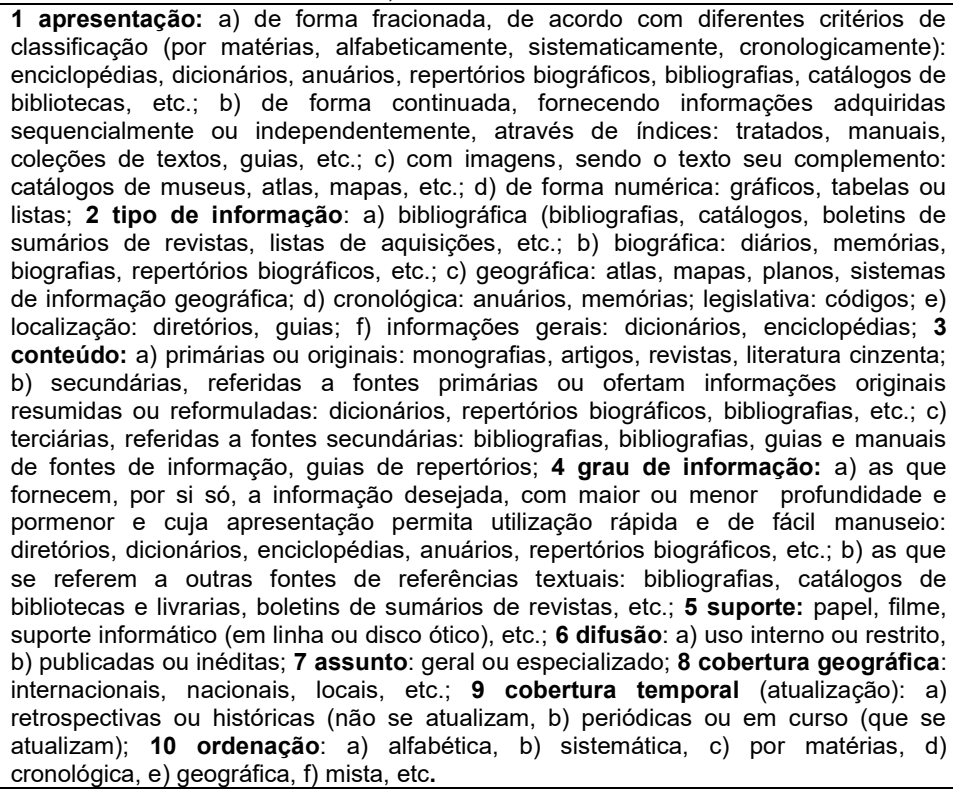 & 2015 & Espanha \\
\hline
\end{tabular}

\section{Fonte: Elaboração Própria}

O quadro apresentado abarca uma variedade de propostas de classificação de fontes e recursos de informação, indicadas por especialistas de línguas e países distintos, com abordagens diferentes, mas integradas no seu contexto geográfico, histórico, científico e tecnológico.

As necessidades de informação encontram respostas nas fontes e recursos de informação. Para a busca, seleção e uso ético dos dados e da informação são necessárias competências, habilidades e atitudes, que se vão ampliando ao longo da vida e de acordo com o desenvolvimento tecnológico. As necessidades de informação determinam as fontes e os recursos que se devem consultar, independentemente das classificações e tipologias. Para clarificar e facilitar a escolha adequada das fontes e recursos a consultar, apresentam-se alguns exemplos no quadro 2. 
Quadro 2- Correspondência entre necessidades e fontes e recursos de informação

\begin{tabular}{|l|l|}
\hline \multicolumn{1}{|c|}{ Necessidades de informação } & \multicolumn{1}{c|}{ Fontes e recursos de informação } \\
\hline $\begin{array}{l}\text { Informações atuais sobre a situação política de um país ou sobre } \\
\text { um desastre que aconteceu em qualquer lugar do mundo }\end{array}$ & $\begin{array}{l}\text { Jornais, revistas, televisão, rádio, redes sociais e outros meios de } \\
\text { comunicação quotidiana. }\end{array}$ \\
\hline $\begin{array}{l}\text { Artigos acadêmicos sobre o uso de mandioca ou componentes da } \\
\text { mandioca }\end{array}$ & Revistas e livros científicos (revistas eletrônicas e livros na web) \\
\hline $\begin{array}{l}\text { Artigos populares sobre fraudes na Internet. } \\
\text { Artigos acadêmicos sobre um tema como a malária, HIV e } \\
\text { tuberculose. }\end{array}$ & $\begin{array}{l}\text { Revistas informativas (revistas eletrônicas na Web) e em bases de dados } \\
\text { (PubMed, MEDLINE, Scopus, Web do Conhecimento, Embase e outras. }\end{array}$ \\
\hline Informação geral como definições, contatos, instituições e outras. & Motores de busca como Google, Yahoo e outros. \\
\hline
\end{tabular}

Fonte: Adaptado de Ajuwon e colaboradores (2011)

Finaliza-se este item com algumas constatações práticas, articuladas com as necessidades de informação de qualquer usuário e as fontes e recursos de informação à sua disposição:

- As fontes e os recursos de informação necessitam de uma análise crítica do usuário, porque trazem abordagem e contexto dos seus criadores. Nesse sentido, podem não ser pertinentes e oportunas aos interesses do usuário, quer nesse momento ou nesse contexto, correndo-se o risco de se usar informação e conhecimento inadequados e inúteis. Por outro lado, podem ter interesses de manipulação cultural, ideológica ou comercial, a maioria das vezes de difícil identificação em leituras efetuadas por usuários com um número limitado de competências.

- As fontes e recursos de informação podem ser primárias, secundárias e terciárias, conforme o objeto e os objetivos da investigação, variáveis quer na mesma ou em diferentes áreas do conhecimento, e dependentes da forma como o material vai ser utilizado e do seu contexto e aplicação.

- Embora o objeto e os objetivos condicionem o tipo de fontes e recursos a utilizar, o investigador deve consultar preferencialmente as fontes primárias adequadas ao seu estudo, para estar mais próximo dos documentos originais correspondentes, e usar diferentes tipos de fontes e recursos de informação, para obter uma visão mais enriquecedora do problema e conhecer os resultados de outras pesquisas da área.

\section{Conclusão}

O presente estudo sobre as fontes e recursos de informação considera a informação na perspectiva da Ciência de Informação e, em particular, da recuperação e uso da informação e reúne classificações propostas por diferentes autores. É indispensável compreender a situação de qualquer usuário que busque resolver suas necessidades de informação, consultando informações em constante crescimento.

No meio acadêmico, compete às instituições de ensino superior preparar estudantes e docentes para a execução das suas atividades individuais, profissionais e sociais, para as quais necessitam de desenvolver o nível das suas capacidades cognitivas, pensamento crítico e competências analíticas.

O novo paradigma educativo universitário requer dos docentes, investigadores e profissionais da informação esforços para preparar os estudantes a procurar, encontrar, avaliar e usar a informação e transformá-la em conhecimento para a tomada de decisões em sua vida individual e profissional, incrementar o gosto pela aprendizagem ao longo da vida e agir como cidadãos ativos e solidários, atuando na construção da sociedade democrática.

Paralelamente, é necessária a formação contínua de bibliotecários das bibliotecas universitárias e dos Centros de Recursos para a Aprendizagem e Investigação (CRAI) no uso de novas ferramentas e recursos de informação, na avaliação e certificação de sua qualidade e fiabilidade, em contextos cada vez mais complexos, usando critérios estritos e sistemáticos, com o apoio de ferramentas específicas.

Por motivos de ordem financeira, política, religiosa e outras, a maioria dos cidadãos do mundo não tem acesso aos meios de comunicação e às fontes e recursos de informação, nem habilidades para resolver suas necessidades de informação, pelo que é imperativo fazer desaparecer esta desigualdade (PNUD, 2015). Usada de forma democrática, a informação serve para tornar a sociedade mais justa, igualitária e desenvolvida. 


\section{Notas}

1. Esta classificação inicial de fontes de informação mantém-se, mas, em 1992, vinte e dois anos depois, Grogan revê-a, inclui alguns aspetos mais complexos dos três tipos de fontes. Especifica que, 1) as fontes primárias discutem ideias novas, interpretações novas sobre acontecimentos importantes ou registros novos com a interferência direta do autor, apresentando, por isso, dificuldade de acesso por estarem dispersas e praticamente fora do sistema de controle bibliográfico; 2) as fontes secundárias são organizados de acordo com critérios definidos, que podem ser alfabético, cronológico ou sistemático, contêm informações filtradas, organizadas e retiradas das fontes primárias, como os dicionários e as enciclopédias; e 3) as fontes terciárias não apresentam conhecimento, por serem, na realidade, guias, direcionadores, sinalizadores para a localização de informação contida nas fontes primárias e secundárias, como os catálogos, diretórios, bibliografias e outras. (GROGAN, D. Science and technology: an introduction to the literature. 2nd.ed. London: C. Bingley, 1992. Cap. I: The literature, p. 14-19.

2. Hiroyuki Itami é um cientista japonês do campo do capital intelectual. A primeira publicação do Mobilizing Invisible Assets (1980) está focada na situação empresarial do seu país. A tradução e adaptação em inglês do livro são de 1987, em coautoria com Thomas W. Roehl da University of Wisconsin-Madison, nos EUA.

3. O último tipo da classificação López Yepes (1989), os sistemas de informação, coincide com a proposta de Burk e Horton (1985).

4. A presente classificação de Martín Vega resulta publicações anteriores, entre outras, o capítulo 2, Ensayo de una tipología documental. Arturo Martín Vega. Fuentes de información general, Gijón: Trea, 1995.

5. Na página 24 da obra consultada, as autoras, Lubisco e Vieira, enumeram três classificações, primárias, secundárias e terciárias. Apenas explicam as primárias e as secundárias, alertando que a variedade de classificações dificulta, muitas vezes, diferenciar as secundárias das terciárias, por se considerar não haver entre elas diferença substancial.

6. Esta classificação de Villaseñor é uma evolução de outra mais simples, cujos critérios são: 1 procedência e origem das fontes e recursos de informação (pessoais, institucionais e documentais); 2 canal de transmissão; 3 cobertura geográfica; 4 grau de adequação; 5 tipo de informação. (VILLASEÑOR RODRÍGUEZ, Isabel Los instrumento para la recuperación de información: las fuentes. In: Las fuentes de información: estudios teóricoprácticos. Madrid: Síntesis, 1999. p. 29-42.

\section{Referências}

AJUWON, G. A. Finding organizing and using health information: a training manual for students, researchers and health workers in Africa. Kanya: Network of African Medical Librarians, 2011. Disponível em:

<http://karibouconnections.net/medlibafrica/training module/index.html.> Acesso em: 24 jan. 2017.

ARRUDA, Susana Margaret; CHAGAS, Joseane. Glossário de biblioteconomia e ciências afins: português - inglês. Florianópolis: Cidade Futura, 2002.

ARROYO VASQUÉZ, N. Fuentes de información en la web social en biblioteconomía y documentación. Interinformación: XI Jornadas Españolas de Documentación: 20, 21 y 22 de mayo de 2009, 2009, ISBN 978-84-692-2663-6, págs. 87-98. Disponível em: <https://dialnet.unirioja.es/servlet/articulo? codigo=2972777>. Acesso em: 24 jan. 2017.

ATHERTON, P. Manual para sistemas y servicios de información. París: UNESCO, 1978.

AYUSO GARCÍA, M. Revisión interdisciplinar de bibliografía y fuentes de información en los umbrales del siglo XXI. Nuevas perspectivas: los recursos de información. Revista General de Información y Documentación, n. 9, Ene. 1999, p. 203-215. Disponível em:<http://revistas.ucm.es/index.php/RGID/article/view/RGID9999120203A>. Acesso em: 24 jan. 2017.

BURK, C. F.; HORTON, E. W. Infornap: a completc guide to discovering corporate information resources. Englewood Ciffs, NJ: Prernice-Hail, 1988, p. 24.

BYSTRÖM, K.; JÄRVELIN, K. Task complexity affects information seeking and use. Information Processing \& Management, v.31, n. 2, p.191-213, Mar. 1995. DOI: https://doi.org/10.1016/0306-4573(95)80035-R. Acesso em: 18 jan. 2017.

CAMPELLO, B. S.; CALDEIRA, P. T. (Org.) Introdução às fontes de informação. Belo Horizonte: Autêntica, 2005.

CAMPELLO, B. S; CALDEIRA, P. T.; MACEDO, V. A. A. (Org.). Formas e expressões do conhecimento: introdução às fontes de informação. Belo Horizonte: Escola de Biblioteconomia da UFMG, 1998.

CAMPELLO, B. S.; CAMPOS, C. M. Fontes de informação especializada; características e utilização. 3. ed. Belo Horizonte: UFMG/PROED, 1988. Disponível em: <http://revista.ibict.br/ciinf/article/viewFile/472/472>. Acesso em: 24 jan. 2017. 
CAMPELLO, B. S.; CENDON, B. V.; KREMER, J. M. Fontes de informação para pesquisadores e profissionais. Belo Horizonte: UFMG, 2000.

CAPURRO, R.; HJORLAND, B. O conceito de informação. Perspectivas em Ciência da Informação, Belo Horizonte, v. 12, n. 1, abr., 2007, p. 148-207. Disponível em: <http://www.scielo.br/pdf/pci/v12n1/11.pdf>. Acesso em: 24 jan. 2017.

CARRIZO, G. S. Las fuentes de información: presente y futuro; algunos apuntes metodológicos. Cuadernos de Documentación Multimedia, Madrid, v.10, p. 399-400, 2000. Disponível em:

<http://pendientedemigracion.ucm.es/info/multidoc/multidoc/revista/num10/paginas/pdfs/Gcarrizo.pdf>. Acesso em: 24 de jan. 2017.

CASTELLS, M. A. Era da informação: economia, sociedade e cultura. Lisboa: Fundação Calouste Gulbenkian, 2002, v. 1.

CASTELLS, M. A sociedade em rede. São Paulo: Paz e Terra, 1999, p. 87.

$\mathrm{CHOO}, \mathrm{C}$. W. Perception and use of information sources in environmental scanning. Library \& Information Science Research, Amsterdam, v. 16, n. 1, p. 23-40, 1994. Disponível em:<http://www.sciencedirect.com/science/article/pii/074081889490040X>. Acesso em: 24 de jan. 2017.

CORNELLÁ, A. La información no es necesariamente conocimiento. Infonomía: la empresa es información. Barcelona: Deusto, 2000. P. 2-8. Disponível em:

<http://aprendeenlinea.udea.edu.co/Ims/investigacion/file.php/3/autocapacitaciones/informacion-conocimiento/capta.pdf.> . Acesso em: 24 jan. 2017.

CUNHA, M. B.. Para saber mais: fontes de informação em ciência e tecnologia. $2^{\mathrm{a}}$ ed. Brasília DF: Briquet de Lemos/ Livros, 2016

CUNHA, M. B. Para saber mais: fontes de informação em ciência e tecnologia. Brasília, DF: Briquet de Lemos/Livros, 2001.

DAVENPORT, T.H.; PRUSAK, L. Working knowledge: how organizations manage what they know. Boston: Harvard Business School, 1998.

DELORS, J. Educação: um tesouro a descobrir. São Paulo: Cortez, 1999

DEVLIN, K. Infoscience: turning information into knowledge. New York: W.H. Freeman, 1999.

FERREIRA, A. B. H. Novo dicionário Aurélio da Língua Portuguesa. Coordenação Marina Baird Ferreira, Margarida dos Anjos. 4. ed. Curitiba: Positivo, 2009.

GARCIA, Thais Xavier. Tecnologias Web 2.0 em unidades de informação: serviços disponibilizados na biblioteca 2.0. Trabalho de Conclusão de Curso (Graduação) - Curso de Biblioteconomia, Departamento de Ciência da Informação, Universidade Federal de Santa Catarina, Florianópolis, 2009 p. 36-37. Disponível em: $<$ http://www.cin.publicacoes.ufsc.br/tccs/cin0041. pdf >. Acesso em: 24 jan. 2017.

GLOSSARY of Library \& Information Science (online). Disponível em:

<https://librarianshipstudies.blogspot.com.br/2016/06/resource-glossary-of-library.html>. Acesso em: 24 de jan. 2017.

GOMES, H. E. O ensino da bibliografia. Revista da Escola de Biblioteconomia da UFMG, Belo Horizonte, v. 5, n. 1, p. 93104, mar. 1976. Disponível em:<http://portaldeperiodicos.eci.ufmg.br/reb/>. Acesso em: 24 jan. 2017.

GROGAN, D. The literature: science and technology: an introduction to the literature. 2nd.ed. London: C. Bingley, 1992. p. 14-19.

GROGAN, D. Science and technology: an introduction to the literature. London: Clive Bingley, 1970. p. 14-15.

HYLÉN, J. Open educational resources: opportunities and challenges. Paris: Organization for Economic Co-operation and Development, 2006. p. 10

IFLA. ISBD (ER) International Standard Bibliographic Description for Electronic Resources, 1997. Disponível em: <http://archive.ifla.org/VII/s13/pubs/isbd.htm>. Acesso em: 25 jan 2017.

ITAMI. H.; ROEHL, T. Mobilizing invisible access. Cambridge, MA: Harvard University, 1987.

JAMIL, G. L; NEVES, J. T. R. A era da informação: considerações sobre o desenvolvimento das tecnologias da informação. Perspectivas em Ciência da Informação, Belo Horizonte, v. 5, n. 1, p. 41 - 53, jan./jun. 2000. . Disponível em: <http://portaldeperiodicos.eci.ufmg.br/index.php/pci/article/view/11>. Acesso em: 24 de jan. 2017.

KATZ, W. A. Introduction to reference work. $8^{\text {th }}$ ed. New York: McGraw-Hill, 2001.

KAYE, D. Sources of information, formal and informal. Management Decision, v. 33, n. 5, p.13-15, 1995. Disponível em: <http://www.emeraldinsight.com/doi/abs/10.1108/EUM0000000003898>. Acesso em: 24 de jan. 2017. 
KRÜGER, K. El concepto de la 'Sociedad del Conocimiento'. Biblio 3W, Revista Bibliográfica de Geografía y Ciencias Sociales, v. 11, n. 683, sep. 2006. Disponível em: <http://www.ub.es/geocrit/b3w-683.htm>. Acesso em: 24 de jan 2017.

LAU, J. Diretrizes sobre desenvolvimento de habilidades em informação para a aprendizagem permanente. Haia: IFLA, 2008. Disponível em: <http://www.ifla.org/files/assets/information-literacy/publications/ifla-guidelines-pt.pdf>. Acesso em: 24 de jan 2017.

LOBO, M. F. T. D; BARCELLOS, S. L. O. Guias de fontes de informação: metodologia para a geração e automação. Ciência da Informação, v. 21, n. 1, p. 75-81, 1992. Disponível em: <http://basessibi.c3sl.ufpr.br/brapci/index.php/article/view/0000002370/25dfba67ee033e6d25fa556f0cbc2ecc>. Acesso em: 3 fev. 2017

LÓPEZ YEPES, J. Introducción al estudio de sistemas de información y documentación en las organizaciones. In:

(Ed.). Fundamentos de información y documentación. Madrid: EUDEMA, 1989, p p. 203-209.

LUBISCO, N. M. L.; VIEIRA, S. C. Manual de estilo acadêmico: trabalhos de conclusão de curso, dissertações e teses. 5. ed. Salvador: EDUFBA, 2013. Disponível em: $<$ http://www.ufal.edu.br/unidadeacademica/ichca/graduacao/jornalismo/documentos/lubisco-2013>. Acesso em: 24 de jan 2017.

LYNCH, C. A. Evolution of networked information resources. In: WILLIAM, M. E., 12th Online Meeting: Proceedings. New York, May 7-9, 1991. Medford, NJ: Leamed Information, 1991.

MARTíN, V. A. Fuentes de información general. Gijón: Trea, 1995, pág. 32-38.

MARTíN, V. A. Las fuentes de información. In: PACIOS LOZANO, Ana Reyes. Técnicas de búsqueda y uso de la información. Madrid: Editorial Universitaria Ramón Areces, 2013, p. 23-43. ISBN: 9788499611266, 8499611265.

MCGARRY, K. O contexto dinâmico da informação: uma análise introdutória. Trad. de Helena Vilar de Lemos. Brasília, DF: Briquet de Lemos/Livros, 1999.

MERLO VEGA, J. A. La colección de referencia. Información y referencia en entornos digitales: desarrollo de servicios bibliotecarios de consulta. Murcia: Universidad de Murcia, 2009.

MERLO VEGA, J. A. La gestión de recursos electrónicos en bibliotecas. Vitoria-Gasteiz, 22 y 23 de febrero, 2007. Curso impartido para el Instituto Vasco de Administración Pública.

MORAES, I. H. S. Política, tecnologia e informação em saúde. Salvador: Casa da Qualidade, 2002, p.48

MOREIRO GONZÁLEZ, J. A. La bibliografía como precedente de la documentación científica: su evolución conceptual. Revista Brasileira de Biblioteconomia e Documentação, São Paulo, v. 22, p. 42-67, 1989.

MOScoso, P. Reflexiones en torno al concepto de "recurso de información". Revista General de Información y Documentación, Madrid, v. 8, n. 1, 1998, p. 331. Disponível em:

<https://revistas.ucm.es/index.php/RGID/article/download/RGID9898120327A/10861>. Acesso em: 24 de jan. 2017.

O'REILLY, T. What Is Web 2.0: design patterns and business models for the next generation of software. 2005. Disponível em: <http://www.oreillynet.com/pub/a/oreilly/tim/news/2005/09/30/what-is-web-20.htm|>. Acesso em: 24 de jan 2017.

OCDE. Knowledge management in the learning society. Paris: 2000.

ODLIS: Online Dictionary of Library and Information Science about the Dictionary. Org. by Joan M. Reitz. 2002, p. 629 Disponível em: <http://vlado.fmf.uni-li.si/pub/networks/data/dic/odlis/odlis.pdf>. Acesso em: 24 de jan. 2017.

OSSIANNILSSON, E.; ALTINAY, Z.; ALTINAY, F. Towards fostering quality in open online education through OER and MOOC practices. Berlin: Springer-Verlag Berlin HeidelbergOpen. p.189-204, 2016. Disponível em: <https://link.springer.com/chapter/10.1007\%2F978-3-662-52925-6 10>. https://doi.org/10.1007\%2F978-3-662-52925-6 10. Acesso em: 24 de jan. 2017

PÁEZ URDANETA, I. Information para el progreso en América Latina. Caracas: Universidad Simón Bolívar, 1990.

PÉREC, G. Penser/classer. Paris: Hachette, 1985.

PELLICER, E, G. La Moda tecnológica en la educación: peligros de un espejismo. In: PÍXEL Bit. Revista de Medios y Educación, n. 9, jun p. 81-92, 1997. Disponível em: <http://www.sav.us.es/pixelbit/pixelbit/articulos/n9/n9art/art97.htm>. Acesso em: 24 de jan. 2017.

PEREIRA, E. C.; BUFREM, L. S. Fontes de informação especializada: uma prática de ensino-aprendizagem com pesquisa na Universidade Federal do Paraná. Perspectivas em Ciência da Informação. Belo Horizonte, v. 7, n. 2, p. 197-206, jul./dez 2002. Disponível em: <http://portaldeperiodicos.eci.ufmg.br/index.php/pci/article/view/408/220>. Acesso em: 24 de jan. 2017. 
PINHEIRO, L. V. R. P. Fontes ou recursos de informação: categorias e evolução conceitual. Pesquisa Brasileira em Ciência da Informação e Biblioteconomia, Rio de Janeiro, v. 1, n. 1, 2006. Disponível em: <http://www.ibict. br/pbcib/include/getdoc. php? Id=76\&article=251\&mode=pdf>. Acesso em: 20 de jan. 2017.

PNUD. La hora de la acción mundial, 2015. Disponível em: <http://www.undp.org/content/dam/undp/library/corporate/UNDP in-action/2015/UNDP AR2015 ES.pdf>. Acesso em: 24 jan. 2017.

REZENDE, D. A.; ABREU, A. F. Tecnologia da Informação aplicada a sistemas de informação empresariais: o papel estratégico da informação e dos sistemas nas empresas. São Paulo: Atlas, 2000, p. 60.

ROMANOS DE TIRATEL, S. Guía de fuentes de información especializadas: humanidades y ciencias sociales. 2. ed. Buenos Aires: GREBYD, 2000. Disponível em:

$<$ http://biblio.colmex.mx/curso investigacion documental/tutorial/PDF/Gu\%C3\%ADa\%20de\%20fuentes.pdf>. Acesso em: 24 de já. 2017.

ROMANOS DE TIRATEL, S. El legado bibliográfico-bibliotecológico de Josefa Emilia Sabor (1916-2012). Información, cultura y sociedade. Buenos Aires, n. 27, p. 11-33, Dic 2012. Disponível em:

<http://www.scielo.org.ar/scielo.php?script=sci arttext\&pid=S1851-17402012000200002\&lng=es\&nrm=iso>. Acesso em: 24 jan. 2017.

SABOR, J. E. Manual de fuentes de información: obras de referencia, enciclopedias, diccionarios, bibliografías, biografias. Buenos Aires: Kapelusz, 1967.

SCHNELLE, H. Information. In: RITTER, J. (Ed). Historichs Worterbuch der Philosophil, IV [Historical dictionary of philosophy, IV] Stuttgart: Schwabe, 1976. p. 116-117.

SEIFFERT, H. Information uber die Information [Information about information]. Munich: Bbeck, 1968.

SHERA, J. H. Los fundamentos de la educación bibliotecológica. México: Centro Universitario de Investigaciones Bibliotecológicas, 1990.

SILVA, L. K. R.; AQUINO, M. A. Sources of information on the Web: Ownership, use and dissemination of racial and ethnic information in the Afro-Brazilian movement from the state of Paraíba, Brazil. Transinformação, Campinas, v. 26, n. 2, p. 203212, ago., 2014. Disponível em:

<http://www.scielo.br/scielo.php?script=sci arttext\&pid=S010337862014000200203\&lng=pt\&nrm=iso>. Acesso em: 8 dez. 2016.

RODRIGUES, C.; BLATTMANN, U. Uso das fontes de informação para a geração de conhecimento organizacional. Perspectivas em Gestão \& Conhecimento, v. 1, n. 2, 2011. Disponível em: <http://www.brapci.ufpr.br/brapci/v/a/12314>. Acesso em: 23 Mar. 2017.

SOPER, M. E.; OSBORNE, L.N.; ZWEIZIG, D.L. The librarians thesaurus. Chicago: American Library Association, 1990.

STACHOKAS, G. A new classification system for free electronic resources. Serials Review, London, v. 38, n. 1, 2012. Disponível em: <http://www.sciencedirect.com/science/article/pii/S0098791311001663>. Acesso em: 24 de jan 2017.

TEXIDOR, S. Recursos electrónicos documentales: nuevos desafíos para el control bibliográfico. Biblios: Revista Electrónica de Ciencias de la Información, v. 4, n. 16, p. 65-80, 2003. <https://dialnet.unirioja.es/descarga/articulo/759414.pdf>. Acesso em: 24 de jan 2017.

TAKAHASHI, T. (Org). Sociedade da informação no Brasil: Livro Verde. Brasília: Ministério da Ciência e Tecnologia, 2000, p. 7. Disponível em: <http://www.instinformatica. pt/servicos/informacao-e-documentacao/biblioteca-digital/gestaoeorganizacao/BRASIL livroverdeSI.pdf>. Acesso em: 24 de jan 2017.

UNESCO. Convite oficial e contexto da Conferência Internacional O Impacto das TICs na Educação, 2010. Disponível em: <http://www.unesco.org/new/pt/brasilia/com-munication-and-information/ict-in-education/international-conference-ict-ineducation/offi-cial-announcement-and-background/\#c154939>. Acesso em: 24 de jan. 2017.

UNESCO/COL. Guidelines for Open Educational Resources (OER) in Higher Education. Paris: UNESCO, 2011, p. 32. Disponível em: <http://unesdoc.unesco.org/images/0021/002136/213605e.pdf>. Acesso em: 24 de jan. 2017.

UNESCO/IFLA. Manifesto UNESCO/IFLA para biblioteca escolar, 2000. Disponível em:<http://www.rbal.com.pt/Documentos\%20RBAL\%20pdf/Manifesto\%20Unesco\%20para\%20Bibliotecas\%20Escolares.pdf>. Acesso em: 24 de jan. 2017.

VILLASEÑOR-RODRÍGUEZ. Los instrumentos para la recuperación de información: las fuentes. TORRES RAMÍREZ, Isabel (Coord.). Las fuentes de información: estudios teórico-prácticos. Madrid: Síntesis, 1999, p. 29-42.

VILLASEÑOR-RODRÍGUEZ, I. Las fuentes de información y de investigación. Educación y Futuro: Revista de Investigación Aplicada y Experiencias Educativas. Madrid, n. 3, Oct. P. 15-32, 2015. Disponível em:

<http://www.cesdonbosco.com/revista/>. Acesso em: 24 jan. 2017. 
WILSON, T.D. On user studies and information needs. Journal of Documentation, 37, 1, pp. 3-15, 1881. Disponível em: < http://informationr.net/tdw/publ/papers/1981infoneeds.html>. Acesso em: 24 jan. 2017.

ZANCANARO, A; TODESCO, J. L; RAMOS, F. A bibliometric mapping of open educational resources. The International Review of Research in Open and Distributed Learning, v. 16, n. 1, jan. 2015. Disponível em:

<http://www.irrodl.org/index.php/irrodl/article/view/1960/3200>. doi: http://dx.doi.org/10.19173/irrodl;v; 16i;1960. Acesso em 5 fev. 2017.

\section{Dados dos autores}

Fernanda Maria Melo Alves

Doctora en Documentación: Archivos y Bibliotecas em Entorno Digital, Universidad Carlos III de Madrid, España. Professora convidada de Pós-graduação em Ciência da Informação da Universidade Federal da Bahia (PPGCI/UFBA), Brasil.

fmeloa2@hotmail.com

Bruno Almeida dos Santos

Mestre em Ciencia de Informação. Pós-graduação em Ciência da Informação da Universidade Federal da Bahia (PPGCI/UFBA), Brasil.

brunosorrisog3@hotmail.com

Recebido - Received: 2017-04-18

Aceitado - Accepted: 2018-02-12

\section{$(\mathrm{cc}) \mathrm{BY}^{\mathrm{B}}$}

This work is licensed under a Creative Commons Attribution 4.0

United States License.

\section{ULIS DDofe}

This journal is published by the University Library System of the University of Pittsburgh as part of its

D-Scribe Digital Publishing Program and is cosponsored by the University of Pittsburgh Press. 